\title{
INFLUENCIA DE LA RADIACIÓN SOLAR EN EL PROCESO DE DEGRADACIÓN Y FRAGMENTACIÓN POST-PEQUEÑA EDAD DEL HIELO DEL GLACIAR DE LA MALADETA (PIRINEO CENTRAL ESPAÑOL)
}

\author{
J. CHUECA CÍA (1) \\ A. JULIÁN ANDRÉS (2)
}

(1) Departamento de Geografía y Ordenación del Territorio; Facultad de Ciencias Humanas y de la Educación; Universidad de Zaragoza; 22002-Huesca

(2) Departamento de Geografía y Ordenación del Territorio; Facultad de Filosofía y Letras; Universidad de Zaragoza; 50009-Zaragoza

Correo electrónico de contacto: jchueca@posta.unizar.es

RESUMEN: El objetivo de este trabajo es analizar el papel de la radiación solar incidente de onda corta en el proceso de degradación y fragmentación observado en el glaciar de la Maladeta desde el último Máximo de la Pequeña Edad del Hielo (PEH) hasta la actualidad. La reconstrucción de la evolución post-PEH del glaciar se efectuó partiendo de la documentación gráfica disponible (iconografía, cartografía topográfica, fotogramas aéreos y fotografias) que ilustraba su estado en distintos momentos de su historia reciente. Los valores de radiación solar han sido estimados a partir de la utilización del programa informático Solar Analyst (ejecutable como una extensión del Sistema de Información Geográfica ArcView), que ofrece la posibilidad de obtener, para cada celda de un Modelo Digital de Elevaciones, valores puntuales de radiación solar directa, difusa y global, así como estimaciones acumuladas de la radiación para períodos de tiempo determinados. Los resultados confirman la fuerte influencia de la radiación solar en la evolución de detalle del glaciar de la Maladeta al propiciar, en función de su intensidad (relacionada con la topografía y el albedo), el desarrollo de áreas con mayor o menor repercusión de los procesos de ablación.

ABSTRACT: The goal of this study is to assess the importance of short-wave solar radiation in the ice wastage processes observed in the Maladeta Glacier since the last Little Ice Age maximum till today. The reconstruction of that evolution was made using different graphic documents (iconography, topographic maps, aerial photographs, terrestrial photographs) that showed the condition of the glacier in several moments of its recent history. The solar radiation values have been obtained by using the Solar Analyst software (an ArcView GIS extension), which calculates estimations of direct, diffuse and global radiation for each cell of a Digital Elevation Model and for selected periods 
of time. The results confirm the strong influence of solar radiation on the detail evolution of Maladeta favoring, as a function of its intensity (related with topography and albedo), the development of areas with differential ablation.

Palabras clave: radiación solar, evolución glaciar, glaciar de la Maladeta, Pirineos. Key words: solar radiation, glacial evolution, Maladeta Glacier, Pyrenees.

Enviado en Julio de 2004

Aceptado en Septiembre de 2004

\section{Introducción}

Los pequeños glaciares de circo son una morfología común en los tramos más elevados de la cordillera pirenaica (Martí-Bono y García-Ruiz, 1994; Chueca et al., 1998). En la vertiente española de los Pirineos, cuatro sectores, todos con altitudes por encima de los $3.000 \mathrm{~m}$, permanecen hoy en día glaciados: son, de oeste a este, los macizos de Infiernos, Monte Perdido, Posets y Maladeta. El macizo de la Maladeta conserva seis glaciares de circo que cubren un área total de aproximadamente $2 \mathrm{~km}^{2}$ (Julián et al., 2001). El objetivo de este trabajo es analizar el papel de la radiación solar incidente de onda corta en el proceso de degradación y fragmentación observado en el glaciar de la Maladeta desde el último Máximo de la Pequeña Edad del Hielo (PEH) hasta la actualidad. En varios estudios previos hemos identificado la importancia en el control de la evolución glaciar, dentro del ámbito pirenaico y para este período, de parámetros climáticos básicos como las temperaturas y las precipitaciones (Chueca et al., 2001, 2003a, b, c; López Moreno et al., 2004a, b). Sin embargo, en glaciares de pequeña extensión y espesor como el aquí analizado, la radiación solar ejerce igualmente un papel básico a la hora de propiciar dentro de ellos el desarrollo de áreas con mayor o menor repercusión de los procesos de degradación y fusión del hielo, matizando la morfología de detalle de cada aparato (Chueca, 1996; Chueca y Julián, 2004).

La reconstrucción de la evolución post-PEH del glaciar de la Maladeta se efectuó partiendo de la documentación gráfica (iconografía, cartografía topográfica, fotogramas aéreos y fotografías) que ilustraba el estado del glaciar en distintos momentos de su historia reciente. Esa documentación, una vez recopilada y analizada, sirvió para realizar la cartografía de la extensión glaciar durante ocho etapas (1857, 1901-04, 1914-20, 1934$35,1957,1981,1990,1997-99)$, a las que se sumaba una inicial (1820-30), datada a partir de los depósitos morrénicos del glaciar correspondientes al último Máximo de la PEH. Los valores de radiación solar han sido estimados a partir de la utilización del programa informático Solar Analyst (ejecutable como una extensión del Sistema de Información Geográfica ArcView), que ofrece la posibilidad de obtener, para cada celda de un Modelo Digital de Elevaciones (MDE), valores puntuales de radiación solar directa, difusa y global, así como estimaciones acumuladas de la radiación para períodos de tiempo determinados.

\section{El área de estudio}

El macizo de la Maladeta se localiza en los Pirineos centrales españoles (Figs. 1 y 2) y es la zona montañosa con mayores alturas de toda la cadena (Aneto, 3.404 m s.n.m.). 


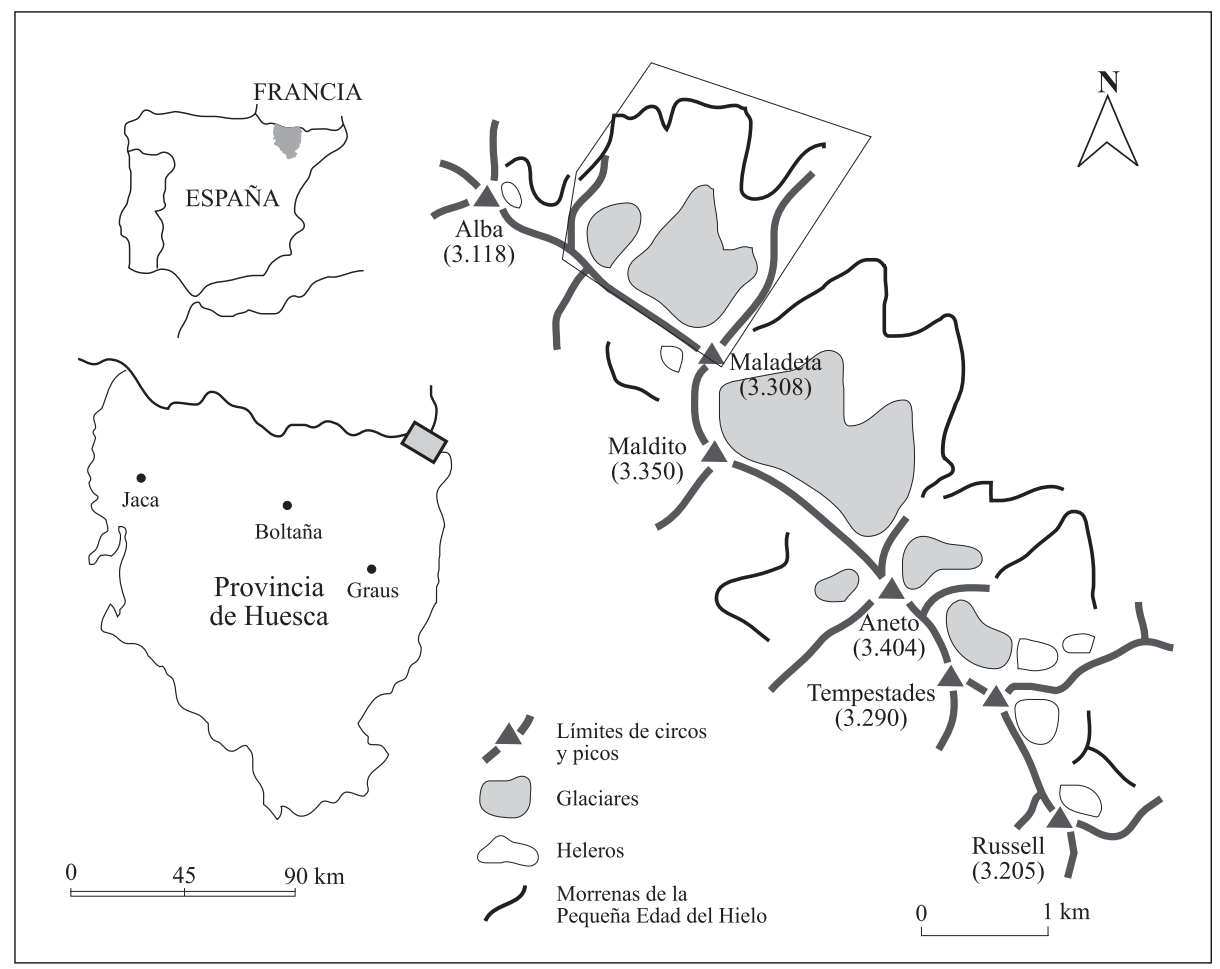

Figura 1. Situación del área de estudio con la localización del circo y glaciares de la Maladeta (en recuadro) en el contexto del macizo.

El modelado glaciar pleistoceno creó los rasgos básicos del paisaje en las cotas más altas, que han ido experimentando transformaciones menores durante el Holoceno asociadas principalmente al desarrollo de procesos de tipo periglaciar y de movilización en masa de los materiales. Dominan las vertientes rocosas desnudas, cubiertas en ocasiones por depósitos morrénicos, mantos de bloques y acumulaciones de origen mixto (gravitacional, por aludes, torrencial). El macizo está formado por granitos y granodioritas muy resistentes, altamente fracturados, pertenecientes al batolito de la Maladeta. La dureza y masividad de estos materiales confiere a la zona su particular morfología, con elevaciones generalizadas por encima de los tres mil metros (Aneto, $3.404 \mathrm{~m}$; Pico Maldito, 3.350 m; Maladeta, 3.308 m; Tempestades, 3.290 m; Pico Russell, 3.205 m; Alba, $3.118 \mathrm{~m}$ ). El circo glaciar analizado se emplaza entre los 2.500-3.300 m, por encima del límite superior de la tree line (situada en el sector hacia los 2.400 m s.n.m.), en el dominio de los pisos geoecológicos alpino, subnival y nival. La temperatura media anual estimada por extrapolación para esta zona varía entre $-2^{\circ} \mathrm{C}$ a los $3.300 \mathrm{~m} \mathrm{y}+2^{\circ} \mathrm{C} \mathrm{a}$ los $2.500 \mathrm{~m}$, y la precipitación anual oscila entre los 2000-2600 mm. La altitud de la línea de equilibrio glaciar en la región se sitúa en la actualidad en torno a los 3.000-3.100 m s.n.m. (Chueca y Julián, 1994). 


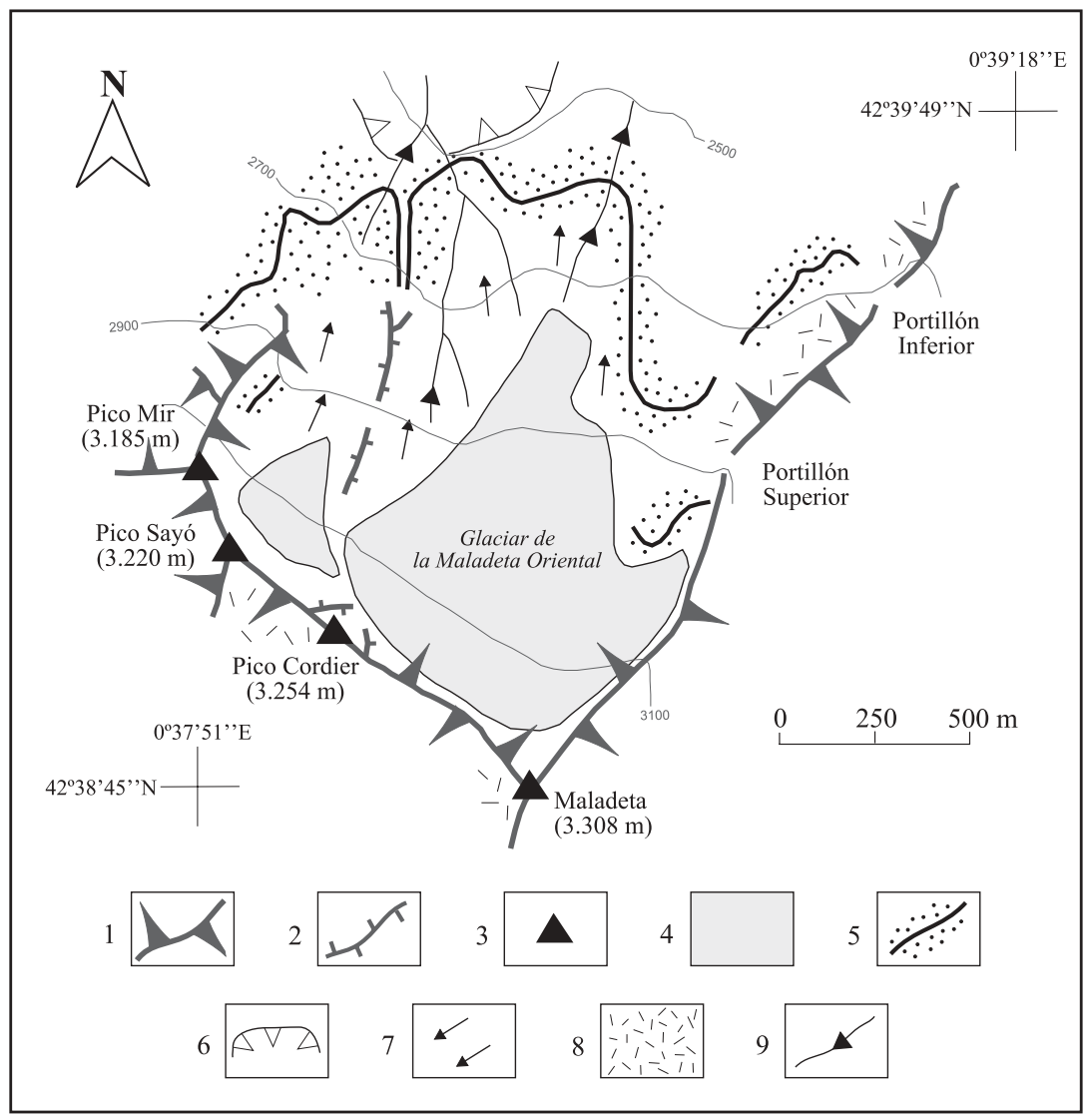

Figura 2. Esquema geomorfológico del circo glaciar de la Maladeta. Leyenda:

1) Cordales de divisoria entre circos; 2) Divisorias menores; 3) Picos principales;

4) Hielo glaciar; 5) Cordones morrénicos y tills de la PEH; 6) Umbrales de origen glaciar; 7) Áreas con sustrato pulido y/o rocas aborregadas; 8) Mantos de derrubios; 9) Red fluvial.

La disposición morfoestructural del macizo de la Maladeta (NO-SE) ha determinado, como en el caso de los macizos glaciados de Infiernos o Monte Perdido, una favorable orientación al NE para la mayoría de los aparatos glaciares hoy catalogados en el sector, que cubren un área de 197,2 ha. Los aparatos glaciares principales son los del Aneto (90,4 ha), Oriental de la Maladeta (48,4 ha), Occidental de Tempestades (14,3 ha), Barrancs (10,8 ha) y Occidental de la Maladeta (6,1 ha). La extensión actual del hielo en el total del macizo, supone tan sólo el $32 \%$ de la que se alcanzó durante el último Máximo de la PEH (616,2 ha). El glaciar de la Maladeta, en particular, que ocupaba en ese momento una superficie de 152,3 ha (el glaciar estaba unido, en aquel momento, al pequeño aparato desarrollado en el vecino circo de Alba), ha pasado, sumando los actua- 
les dos fragmentos, a 54,5 ha, el 35,7\% de esa extensión inicial. Pese a las marcadas pérdidas en extensión y espesor, ambos glaciares (aunque fundamentalmente el Oriental, de mayores dimensiones) todavía exhiben un apreciable dinamismo, con desarrollo puntual de grietas de tracción longitudinales y transversales de anchura y profundidad métricas. Los trabajos de Martínez y García (1994) y Martínez et al. (1997), en los que, mediante prospección geofísica, se analizaron los espesores de hielo en ambos cuerpos de hielo, arrojaron valores máximos ligeramente superiores a los $50 \mathrm{~m}$ en el caso del glaciar Oriental (en su sector proximal más oriental, al pie del pico de la Maladeta) y a los 30 m en el del glaciar Occidental (en su sector proximal más occidental).

\section{Métodos}

\subsection{Reconstrucción de la evolución glaciar}

La reconstrucción de la evolución del glaciar de la Maladeta ha sido ya expuesta con detalle en Chueca et al. (2003b), y se basa en la metodología adoptada en un trabajo previo llevado a cabo en el vecino glaciar de Coronas (Chueca et al., 2001). El estudio de la evolución y la dinámica glaciar desde la PEH y hasta la actualidad en el macizo de la Maladeta ha sido abordado igualmente con mayor o menor nivel de precisión en varios trabajos previos de distintos autores (Martínez de Pisón y Arenillas, 1988; Copons y Bordonau, 1994, 1997; Lampre, 1994, 1996; Chueca y Julián, 1996).

A excepción de la primera de las etapas estudiadas, datada a partir de los materiales morrénicos de la PEH presentes en el circo (Chueca y Julián, 1996), se han examinado y/o utilizado en la cartografía de la extensión del hielo, siempre que presentaran fiabilidad suficiente, distintas fuentes:

1) Iconografía (grabados y dibujos de época): aunque no se han empleado directamente en la cartografía de la extensión glaciar, sí se han consultado como apoyo de otros documentos. La iconografía analizada incluye los dibujos de la vertiente norte del macizo hechos por Fiedrich Parrot hacia 1820 (Parrot, 1823), los grabados realizados hacia 1850-60 por el litógrafo Victor Petit para la Guide Joanne (Joanne, 1862), y la litografía de ese mismo sector efectuada en 1856 por Edouard Paris.

2) Mapas topográficos: existen para la zona distintas ediciones españolas y francesas. Por su escala, la fiabilidad en la cartografía del hielo glaciar es muy baja, y sólo se han utilizado como documentos de apoyo. Además, la mayoría de estos documentos topográficos cubren únicamente la segunda mitad del siglo XX (con la excepción de los levantamientos cartográficos efectuados en el macizo de la Maladeta por Charles Packe y Franz Schrader en torno a 1867 y 1890, respectivamente; Packe, 1867, Schrader, 1894), etapa para la hay disponibles fuentes más precisas.

3) Fotografías aéreas: su fiabilidad es manifiesta, aunque su utilidad se ve reducida si en el momento de la toma de los fotogramas la innivación era importante, enmascarando la extensión real de los aparatos glaciares. En este sentido, los fotogramas del vuelo de 1957 son los únicos que se han utilizado sin reservas (vuelo americano; Agosto, 
1957; escala 1:30.000; blanco y negro). Vuelos posteriores, como los de 1981 (vuelo Pirineos Sur; Septiembre, 1981; escala 1:25.000; blanco y negro) ó 1997 (vuelo Gobierno de Aragón; Agosto-Septiembre, 1997-2000; escala 1:20.000; color), más detallados pero con mayor presencia de la cobertera nival, tan sólo se han empleado como apoyo a las interpretaciones del cuarto tipo de documentos.

4) Fotografías convencionales: constituyen uno de los documentos más útiles si los lugares desde donde se efectuaron las tomas son similares y las imágenes significativas (abarcan gran parte del cuerpo glaciar y distintos elementos de la caja glaciar utilizables como referencia en los procesos de restitución; la innivación es reducida). El único problema grave está ligado al correcto establecimiento de la fecha de su toma, problema que se acentúa en los documentos más antiguos. Las fotografías utilizadas en nuestro estudio son, por tanto, sólo aquellas para las que contamos con una cronología contrastada y fiable y cumplen los requisitos mencionados (en caso contrario se utilizan como simples documentos de apoyo). El número de documentos antiguos empleados en la reconstrucción de la evolución del glaciar de la Maladeta incluye fotografías de 1857 (A. Civiale), 1876 (E. Trutat), 1901 (J. Soler Santaló), 1904 (L. le Bondidier), 1914 (postales anónimas editadas como colección por Catalana de Gas y Electricidad), 1920 (C. Lana), 1934 (R. Compairé) y 1935 (L. García Sainz). Para las últimas tres décadas el número de fotografías disponibles aumenta, habiéndose utilizado fotografías de nuestra colección particular y de la base de datos del proyecto de investigación Estudio de la dinámica de los glaciares del Pirineo aragonés, que coordina campañas glaciológicas en la zona desde 1992.

\subsection{Estimación de la radiación solar}

Los estudios sobre radiación solar y procesos glaciares asociados son hasta la fecha muy escasos en la cordillera pirenaica. Pueden mencionarse los de Chueca (1996), que analizó la relación entre la morfología bilobulada del glaciar del Aneto y los valores de radiación; y el de Chueca y Julián (2004), en el que se valoraba la influencia de la distribución espacial de la radiación solar en el desarrollo y evolución glaciar de los glaciares de circo del Aneto, Coronas y Llosás. La radiación solar es determinante para numerosos procesos físicos y biológicos que se producen en nuestro planeta y, entre otros, condiciona las pautas de fusión en superficies glaciares. La interacción de la radiación solar con la atmósfera y la superficie de la tierra depende de diversos factores entre los que se incluyen: la geometría, revolución y rotación de la Tierra (declinación, latitud y variación del ángulo solar); topografía del terreno (altitud, pendiente, orientación y sombras); y el efecto atenuador de la atmósfera debido a la presencia de gases, partículas y nubosidad. A escala regional y local, especialmente en áreas montañosas, la topografía es, sin duda, el factor fundamental en la distribución de la radiación solar, al que ha de sumarse el efecto albedo producido por las diferentes superficies y cubiertas sobre las que incide la radiación (Iqbal, 1983; Funk y Hoelzle, 1992; Varley y Beven, 1996).

Los modelos de estimación de radiación solar pueden incluirse en dos grandes categorías: los tradicionales basados en la estimación puntual y los más recientes basados en la estimación por áreas: 
1) Los modelos de estimación puntual (point-specific models) computan la insolación para una localización concreta basándose en la geometría de la orientación de esa superficie y el cielo visible desde la misma; el efecto local de la topografía se considera a partir de relaciones empíricas (Flint y Childs, 1987; Rich et al. 1994);

2) Los modelos de estimación por áreas (area-based models), por el contrario, calculan la insolación para un área geográfica determinada partiendo de los datos de geometría del terreno aportados por un modelo digital de elevaciones (Hetrick et al. 1993; Dubayah y Rich 1995; Heggem et al. 2001).

En nuestro caso hemos optado por esta segunda aproximación, utilizando el programa informático Solar Analyst, ejecutable como una extensión del SIG ArcView (Fu y Rich, 2000), que ofrece la posibilidad de obtener, para cada celda de un MDE, valores puntuales de radiación solar directa, difusa y global, así como estimaciones acumuladas de la radiación para períodos de tiempo determinados. En el proceso de cálculo, el programa genera una panorámica hemiesférica desde cada ubicación y considera la latitud, altitud, orientación, efecto de las sombras por la topografía circundante, cambios en el ángulo solar diarios y estacionales, y el efecto de la atmósfera. Los requerimientos básicos son, por tanto, disponer de un MDE de la zona de estudio y de unos valores representativos de transmisividad atmosférica y de proporción de radiación difusa.

El MDE utilizado se realizó tomando como base la altimetría digital a escala 1:25.000 que suministra el Instituto Geográfico Nacional (cuadrantes I y II correspondientes a la Hoja 180-Benasque, del Mapa Topográfico Nacional escala 1:50.000). A partir de la interpolación de las curvas de nivel y de las cotas, se obtuvo una red irregular de triángulos (TIN) que fue convertida a un formato grid con una resolución de 10 $\mathrm{m}$. De este MDE se derivaron los mapas de pendientes y de orientaciones, necesarios para que el programa de radiación efectúe los cálculos. En cuanto a los valores de transmisividad atmosférica y de proporción de la radiación difusa, dado que no existen estaciones meteorológicas próximas que suministren este tipo de información, se aplicaron los valores estándares aconsejados de 0,5 y 0,3 respectivamente, correspondientes a unas condiciones de cielo generalmente despejado.

\section{Resultados y discusión}

\subsection{Evolución glaciar}

Los rasgos básicos del glaciar de la Maladeta en cada una de las nueve etapas que hemos analizado pueden sintetizarse, a partir del trabajo de Chueca et al. (2003b), del siguiente modo (Fig. 3; Tabla 1):

1) Situación en 1820-30: esta etapa aparece representada por el potente cordón morrénico que se dispone entre los 2.500-2.800 m s.n.m. en el tramo distal del circo de la Maladeta, e indica el momento de inicio del proceso de deglaciación que ha ido experimentando el glaciar de la Maladeta hasta la fecha (de hecho, en esta fase el glaciar estaba, aunque de forma marginal, unido al pequeño cuerpo de hielo desarrollado en el circo 


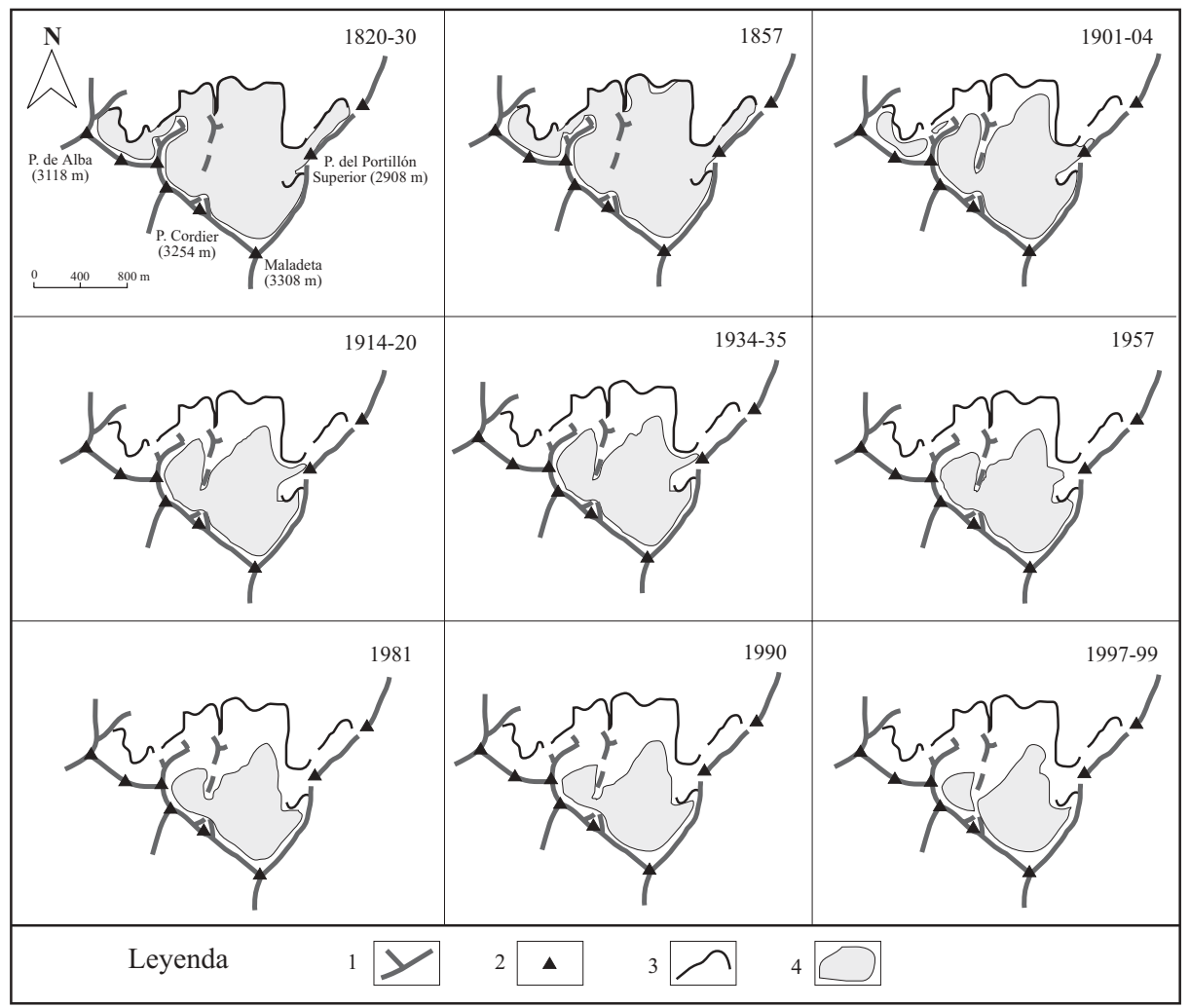

Figura 3. Cartografía de la evolución del glaciar de la Madaleta en las nueve etapas analizadas. Leyenda: 1) Cordales de divisoria entre circos; 2) Picos principales;

3) Cordones morrénicos de la PEH; 4) Hielo glaciar.

de Alba, situado al oeste del de la Maladeta). La extensión del glaciar en aquel momento (incluyendo el tramo que pertenece al citado circo de Alba y su prolongación hacia el de la Maladeta bajo el Pico Mir) alcanzaba las 152,3 ha, con una longitud de $1.560 \mathrm{~m}$, y unas cotas máxima y mínima de presencia de hielo de 3.220 y 2.510 m s.n.m., respectivamente; la línea de equilibrio glaciar (ELA), calculada para ese momento por el método de Kurowski, se situaba en los 2.840 m.

2) Situación en 1857: en ese momento, el glaciar de la Maladeta apenas evidenciaba retroceso en extensión respecto al máximo de la etapa anterior (tasa de pérdida de superficie de -0,11 ha/año). El cuerpo del glaciar había perdido contacto con la morrena únicamente en algunos tramos muy puntuales de su extremo fronto-distal (Fig. 4). Su extensión era de 148,5 ha, con una longitud cercana a los $1.540 \mathrm{~m}$, y una localización de sus cotas altitudinales máxima y mínima y de su ELA similares a las de la etapa anterior. 
Tabla 1. Características básicas del glaciar de la Maladeta durante las etapas analizadas.

\begin{tabular}{|c|c|c|c|c|c|c|c|c|c|}
\hline & $1820-30$ & 1857 & 1901-04 & $1914-20$ & $1934-35$ & 1957 & 1981 & 1990 & 1997-99 \\
\hline \multirow{2}{*}{$\begin{array}{l}\text { Sup Oc. Maladeta (ha) } \\
\text { Or. Maladeta }\end{array}$} & \multirow{2}{*}{152,3} & \multirow[t]{2}{*}{148,5} & \multirow[t]{2}{*}{100,7} & \multirow[t]{2}{*}{92,9} & \multirow[t]{2}{*}{89,7} & \multirow[t]{2}{*}{74,2} & \multirow[t]{2}{*}{70,9} & \multirow[t]{2}{*}{61,6} & 6,1 \\
\hline & & & & & & & & & 48,4 \\
\hline$\%$ Superficie inicial & 100 & 97,5 & 66,1 & 60,9 & 58,8 & 48,7 & 46,5 & 40,4 & 35,7 \\
\hline $\begin{array}{l}\text { Tasa pérdida sup. } \\
\text { (ha/año) }\end{array}$ & & $-0,11$ & $-1,03$ & $-0,55$ & $-0,18$ & $-0,68$ & $-0,13$ & $-1,03$ & $-0,88$ \\
\hline \multirow[t]{2}{*}{ Alt. máx. (m) } & \multirow[t]{2}{*}{3.220} & \multirow[t]{2}{*}{3.220} & \multirow[t]{2}{*}{3.200} & \multirow[t]{2}{*}{3.200} & \multirow[t]{2}{*}{3.200} & \multirow[t]{2}{*}{3.200} & \multirow[t]{2}{*}{3.200} & \multirow[t]{2}{*}{3.200} & Oc. 3.180 \\
\hline & & & & & & & & & Or. 3.200 \\
\hline \multirow[t]{2}{*}{ Alt. mín. (m) } & \multirow[t]{2}{*}{2.510} & \multirow[t]{2}{*}{2.510} & \multirow[t]{2}{*}{2.640} & \multirow[t]{2}{*}{2.660} & \multirow[t]{2}{*}{2.670} & \multirow[t]{2}{*}{2.700} & \multirow[t]{2}{*}{2.710} & \multirow[t]{2}{*}{2.730} & Oc. 2.910 \\
\hline & & & & & & & & & Or. 2.740 \\
\hline \multirow[t]{2}{*}{ Long. máx. (m) } & \multirow[t]{2}{*}{1.560} & \multirow[t]{2}{*}{1.540} & \multirow[t]{2}{*}{1.540} & \multirow[t]{2}{*}{1.340} & \multirow[t]{2}{*}{1.300} & \multirow[t]{2}{*}{1.220} & \multirow[t]{2}{*}{1.200} & \multirow[t]{2}{*}{1.100} & Oc. 380 \\
\hline & & & & & & & & & Or. 1.030 \\
\hline ELA (m) & 2.840 & 2.840 & 2.980 & 3.005 & 3.010 & 3.030 & 3.035 & 3.090 & 3.095 \\
\hline
\end{tabular}

3) Situación en 1901-04: la extensión del cuerpo de hielo muestra una disminución notable, con una tasa de pérdida de superficie de $-1,03$ ha/año desde la etapa anterior, alcanza una cifra de 100,7 ha (66,1\% de la inicial). Las cotas de localización altitudinal máxima y mínima evolucionan obviamente de forma regresiva, pasando a ser, respectivamente de 3.200 y 2.640 m s.n.m., mientras que la longitud máxima, con $1.540 \mathrm{~m}$, sigue siendo muy similar a la del máximo. La línea de equilibrio glaciar se emplaza en esta fase a $2.980 \mathrm{~m}$ s.n.m.

4) Situación en 1914-20: durante las dos décadas transcurridas, el glaciar de la Maladeta mantuvo una tasa de pérdida de superficie elevada aunque algo ralentizada (-0,55 ha/año), situándose en 92,9 ha (60,9\% de la inicial). El retroceso en longitud se remarca, quedando este parámetro en $1.340 \mathrm{~m}$, con cotas altitudinales máximas y mínimas de 3.200 y 2.660 m s.n.m., respectivamente. La ELA se ubicaba en esta etapa a 3.005 m s.n.m.

5) Situación en 1934-35: entre esta etapa y la anterior, el glaciar de la Maladeta pierde superficie a un ritmo menor (-0,18 ha/año), quedando ésta en 89,7 ha $(58,8 \%$ de la inicial). Su longitud era de $1.300 \mathrm{~m}$ y sus cotas de localización altitudinal de $3.200 \mathrm{y}$ 2.670 m s.n.m., emplazándose entonces su línea de equilibrio a 3.010 m de altura.

6) Situación en 1957: la tasa de retroceso evidenciada en la fase anterior se hace, algo más de veinte años después, mucho más marcada (-0,68 ha/año). El cuerpo de hielo tiene ahora una extensión de 74,2 ha (el 48,7\% de la inicial), con una longitud máxima de unos 1.220 m y cotas máxima y mínima de 3.200 y 2.700 m s.n.m., respectivamente. La línea de equilibrio glaciar se sitúa en esta fase en torno a los 3.030 m s.n.m. 


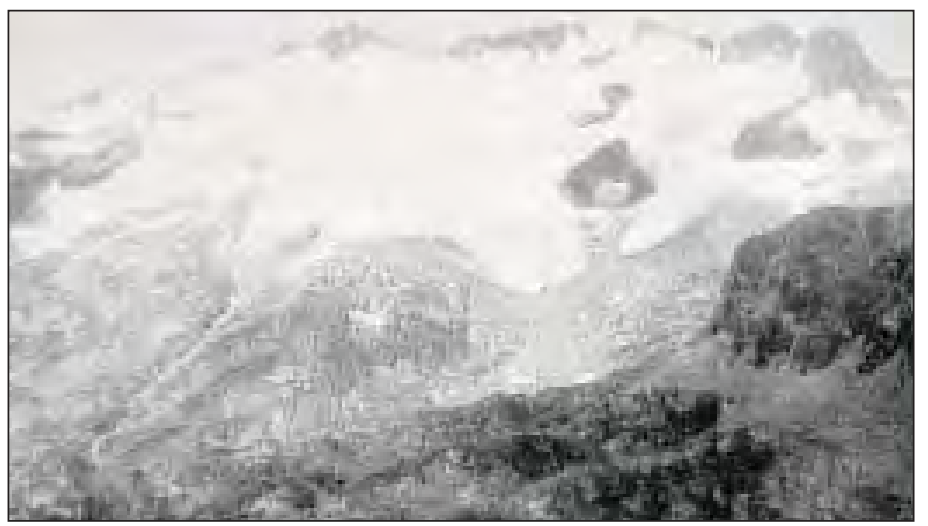

Figura 4. Panorámica del glaciar de la Maladeta desde el Puerto de Benasque (Autor: A. Civiale; Fecha: 1857).

7) Situación en 1981: el hecho más llamativo es el marcado atenuamiento experimentado en las pautas de retroceso de superficie y espesor que hasta ese momento se habían venido registrando en el glaciar, sin precedentes desde mediados del siglo XIX: así, el deterioro cuantificado en el cuerpo de hielo desde 1957, durante un lapso de tiempo de algo más de dos décadas, se reduce a una tasa de pérdida de superficie de $-0,13$ ha/año, la segunda cifra más baja de todo el período considerado. El cuerpo principal pierde apenas 3,3 ha de extensión, quedándose en 70,9 ha (46,5\% de la superficie inicial); las cotas máximas y mínima, la longitud y la altitud de localización de la ELA no resgistran apenas variaciones significativas, manteniéndose casi en los mismo valores de la etapa anterior.

8) Situación en 1990: El glaciar registró, en los diez años transcurridos desde la etapa anterior, los valores más altos de tasa de pérdida de superficie (-1,03 ha/año), prácticamente un orden de magnitud superiores a los de la fase previa y similares a los ya mencionados para el período 1857-1901/04, al comienzo del proceso de deglaciación tras el último Máximo de la PEH. La separación entre los actuales dos fragmentos (glaciares Occidental y Oriental de la Maladeta) todavía no llega a constatarse. La extensión del cuerpo de hielo en este momento era de 61,6 ha (el 40,4\% de la la inicial), con una longitud máxima de $1.100 \mathrm{~m}$ y cotas máxima y mínima emplazadas a 3.200 y $2.730 \mathrm{~m}$ s.n.m., respectivamente. La línea de equilibrio glaciar ascendía varias decenas de metros, hasta situarse en los $3.090 \mathrm{~m}$.

9) Situación en 1997-99: a finales del siglo XX, el glaciar de la Maladeta se presenta definitivamente desgajado en dos cuerpos, los glaciares Occidental y Oriental de la Maladeta (Figs. 5 y 6). El glaciar Occidental, el de menores dimensiones, posee 6,1 ha de superficie, y el Oriental, 48,4 ha; la suma de ambos, 54,5 ha, supone el 35,7\% de la superficie inicial del glaciar. La tasa de pérdida de superficie en la década de los noven- 


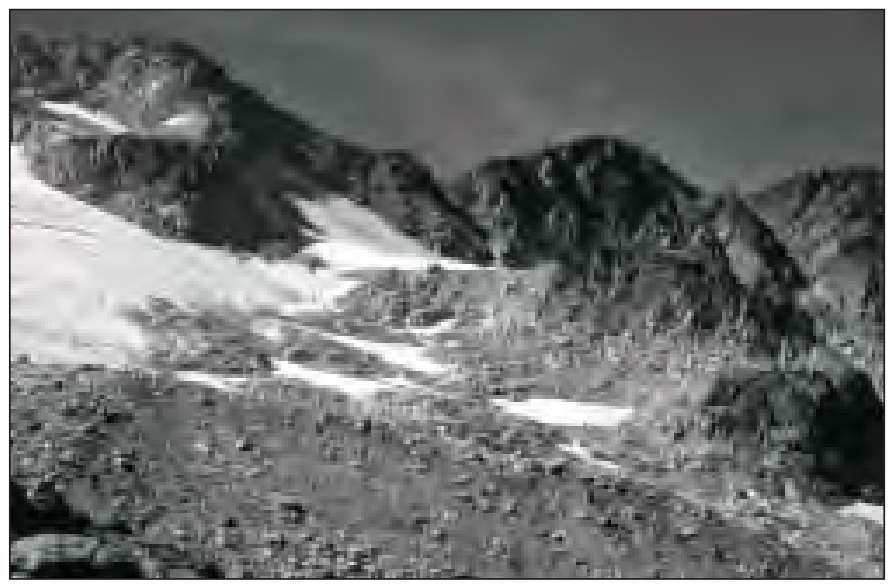

Figura 5. Detalle de la fragmentación del glaciar de la Maladeta en los dos cuerpos actuales a mediados de los años noventa: a la derecha el glaciar Occidental y a la izquierda el glaciar Oriental. En primer término se aprecia el cordón morrénico de la PEH.

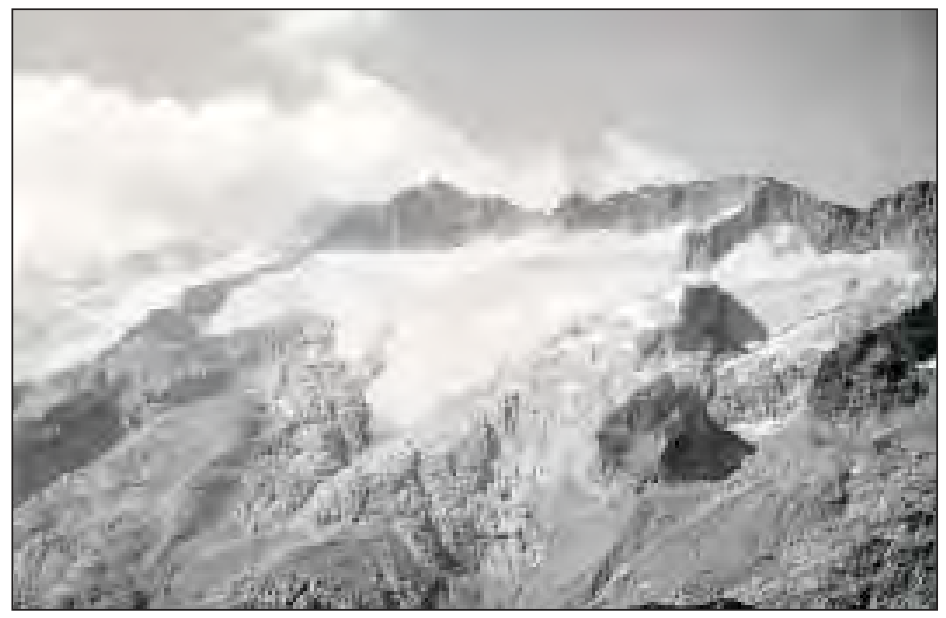

Figura 6. Panorámica de los glaciares de la Maladeta desde el Puerto de Benasque (Autor: J. Camins; Fecha: 1999).

ta, aunque algo menos marcada que en la década anterior, sigue siendo una de las elevadas de todo el período estudiado: -0,88 ha/año. El glaciar Occidental presenta una longitud de 380 m y cotas máxima y mínima de presencia de hielo situadas a 3.180 y 2.910 m s.n.m., respectivamente. El glaciar Oriental tiene una longitud máxima de $1.030 \mathrm{~m}$, su altura máxima y mínima es de 3.200 y 2.740 m s.n.m., y la línea de equilibrio glaciar se ubica a 3.095 m s.n.m. 
En suma, el análisis de la tasa de pérdida de superficie permite identificar una serie de fases de: 1) estabilización glaciar (1820-30 a 1857; 1914-20 a 1934-35; 1957 a 1981); 2) pérdida moderada de extensión (1901-04 a 1914-20; 1934-35 a 1957); y 3) pérdida marcada de extensión (1857 a 1901-04; 1981 a 1997-99).

\subsection{Relación entre radiación solar y degradación y fragmentación glaciar}

En varios trabajos previos hemos apuntado la importancia en el control de la evolución glaciar, dentro del ámbito del macizo de la Maladeta y para el período posterior al último Máximo de la $\mathrm{PEH}$, de parámetros climáticos básicos como las temperaturas y las precipitaciones (Chueca et al., 2001, 2003a, b, c; López Moreno et al., 2004 a, b). Las modificaciones por encima o por debajo de los valores de referencia, tanto de los valores térmicos anuales y de verano, como de las precipitaciones anuales y de invierno, tienen su reflejo en las fases de retroceso o estabilización detectadas en los glaciares de Coronas y de la Maladeta. Particularmente evidentes son las relaciones clima-dinámica glaciar en los episodios mencionados de pérdida marcada de extensión y en los de estabilización.

De forma complementaria, en glaciares de pequeña extensión y espesor como los pirenaicos, la radiación solar ejerce igualmente un papel básico a la hora de propiciar dentro de ellos el desarrollo de áreas con mayor o menor repercusión de los procesos de degradación y fusión del hielo, matizando la morfología de detalle de cada aparato. Buenos ejemplos son el glaciar del Aneto, con una marcada morfología bilobulada relacionada con la existencia de procesos de ablación acentuados en la zona central del circo (Chueca, 1996), o los de Coronas y Llosás, cuyo desarrollo durante la PEH se apoya en la existencia de valores bajos de radiación en determinados sectores de sus circos glaciares (Chueca y Julián, 2004).

Los valores de radiación obtenidos muestran la existencia en el circo de la Maladeta de importantes variaciones sectoriales y temporales en los aportes de energía recibidos. En la cartografía presentada en las Figuras 7-11 aparecen las estimaciones de radiación global (expresada en $\mathrm{Whm}^{-2}$ o en $\mathrm{KWhm}^{-2}$ ) efectuadas para cinco momentos del año significativos: 1) total estival (entre el 21 de junio y el 22 de septiembre); 2) solsticio de verano (21 de junio); 3) total invernal (entre el 22 de diciembre y el 20 de marzo); 4) solsticio de invierno (22 de diciembre); y 5) total anual. Conocer la distribución espacial de los valores de radiación estivales, el período con albedos reducidos en el que son dominantes los procesos de fusión de la nieve y el hielo glaciar es básico y, en términos de balance de masa glaciar, presenta igualmente gran interés conocer el comportamiento espacial de la radiación solar incidente en la época invernal, con albedos altos, al controlar este parámetro en parte la acumulación potencial de la nieve en áreas preferenciales del glaciar. Ambos períodos se complementan, al representar respectivamente las variaciones espaciales en las entradas de radiación durante las fases anuales dominantes de ablación y acumulación. Adicionalmente, el cálculo de la radiación total anual acumulada es, aparte de interesante de por sí al evidenciar el patrón de comportamiento radiativo anual, un útil valor de referencia estándar para realizar comparaciones con otros ámbitos alpinos. 


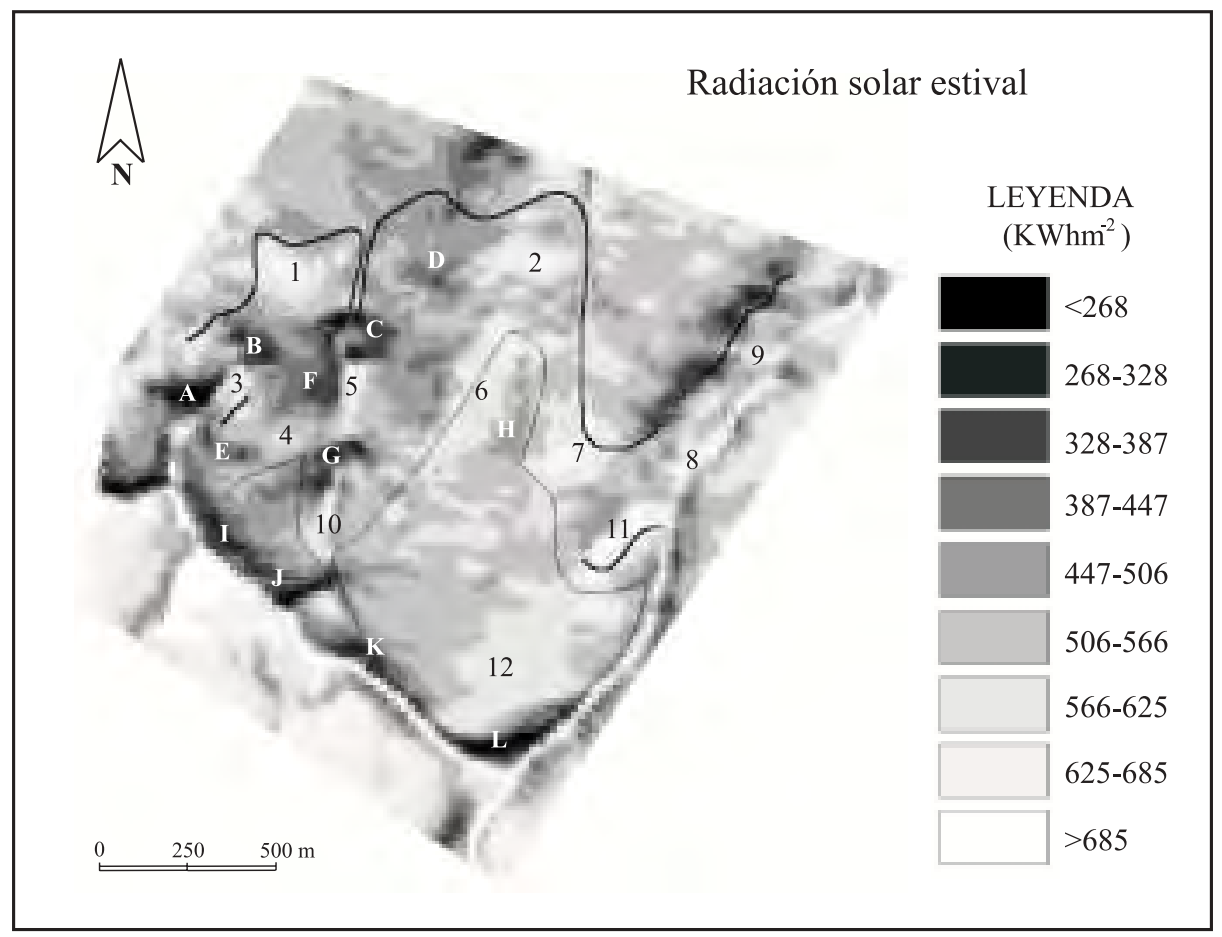

Figura 7. Cartografía de la radiación solar estival. Aparecen indicados los sectores con valores de radiación elevados (1-12) y reducidos (A-L) que se comentan en el texto.

De cara al comentario de la cartografía, y aprovechando los patrones generales de distribución espacial de la radiación que se identifican en todos los mapas, en la Figura 7 se han señalado dos tipos de sectores: 1) sectores con valores de radiación elevados (112); 2) sectores con valores de radiación reducidos (A-L). En las tablas 2 y 3 se recogen, respectivamente, los valores de radiación máximos y mínimos absolutos para cada uno de los dos tipos de sectores y en cada uno de los cinco períodos estudiados. El análisis del comportamiento de la radiación en esas zonas ayuda a entender la evolución del glaciar desde el último Máximo de la PEH.

\subsubsection{Sectores con valores de radiación elevados}

Se han destacado en la cartografía 12 sectores del circo de la Maladeta (sectores 112) que reciben, sea cual sea la época del año analizada, valores de radiación comparativamente más altos que los estimados para el resto del ámbito de estudio (Figs. 7-11; Tabla 2). Los sectores 1, 8 y 9 fueron las primeras zonas en las que desapareció hielo en el glaciar tras el último Máximo de la PEH, mostrándose deglaciadas en 1901-04. 


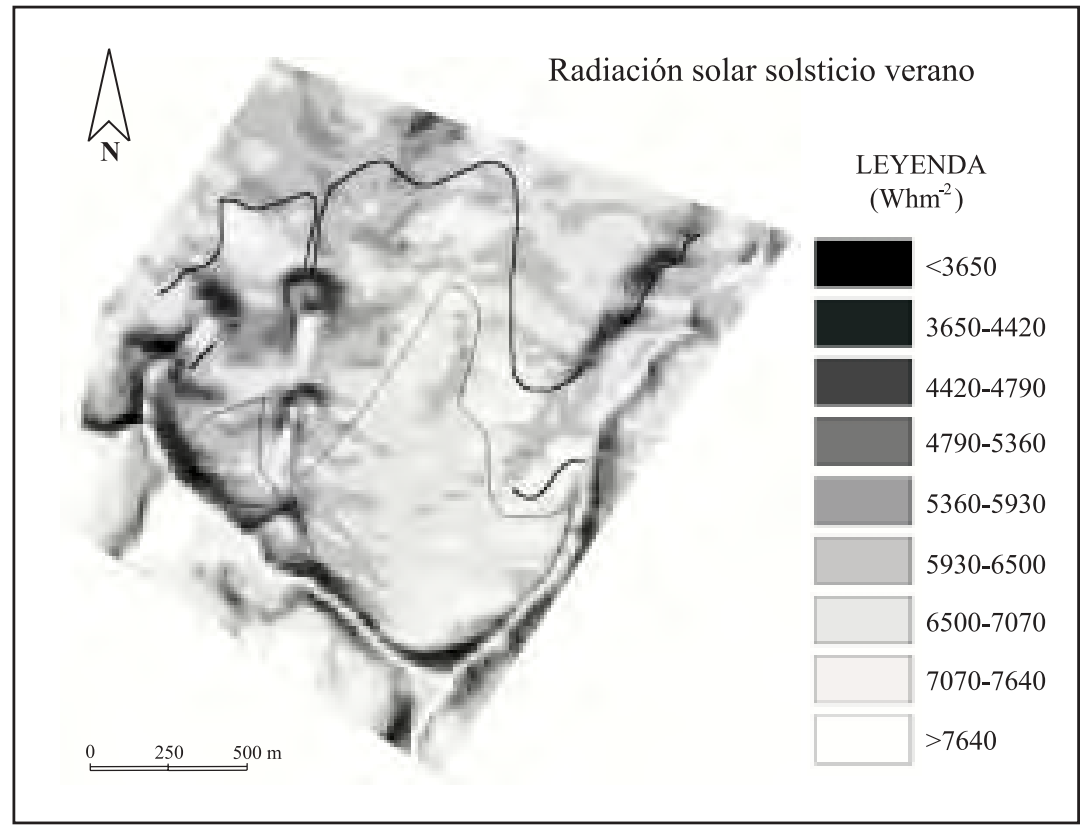

Figura 8. Cartografía de la radiación solar en el solsticio de verano.

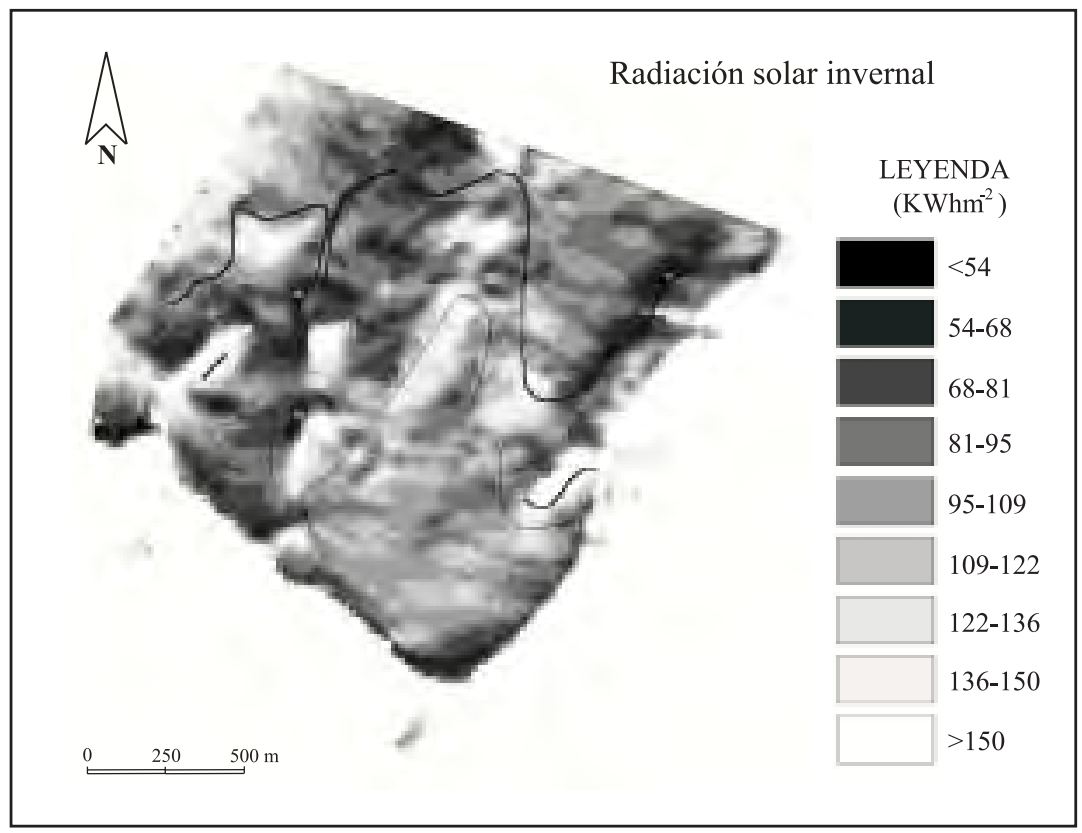

Figura 9. Cartografía de la radiación solar invernal. 


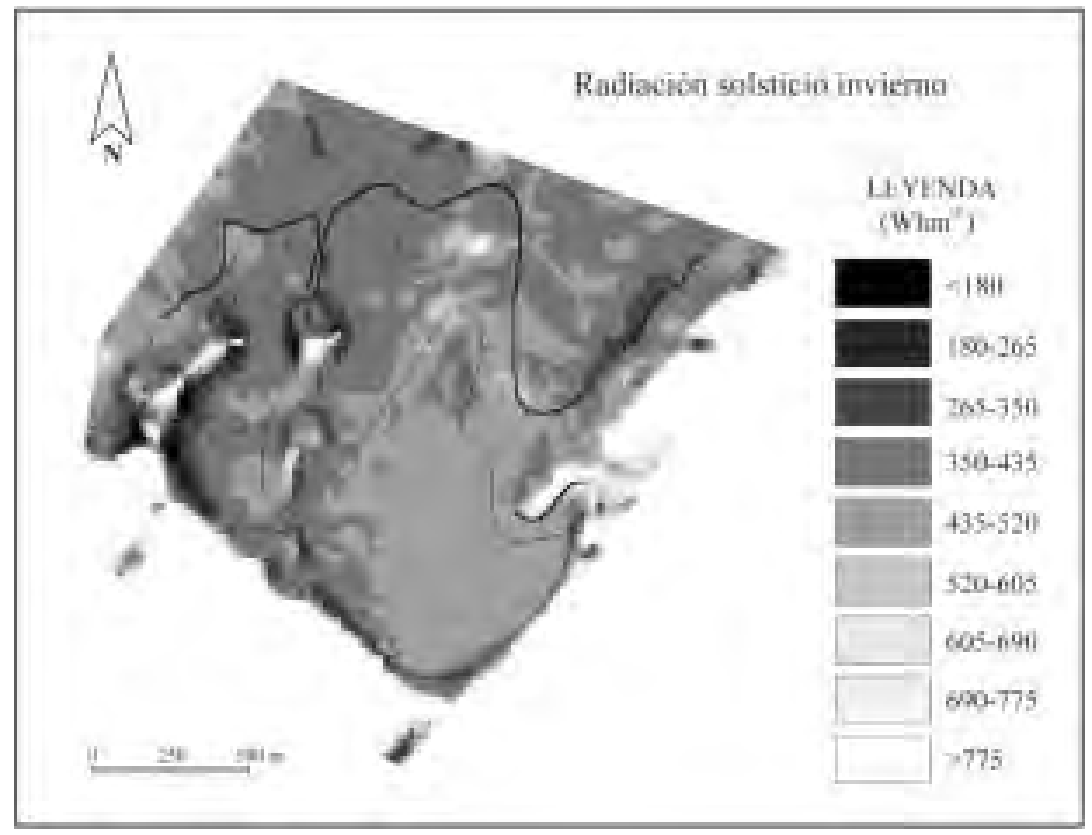

Figura 10. Cartografía de la radiación solar en el solsticio de invierno.

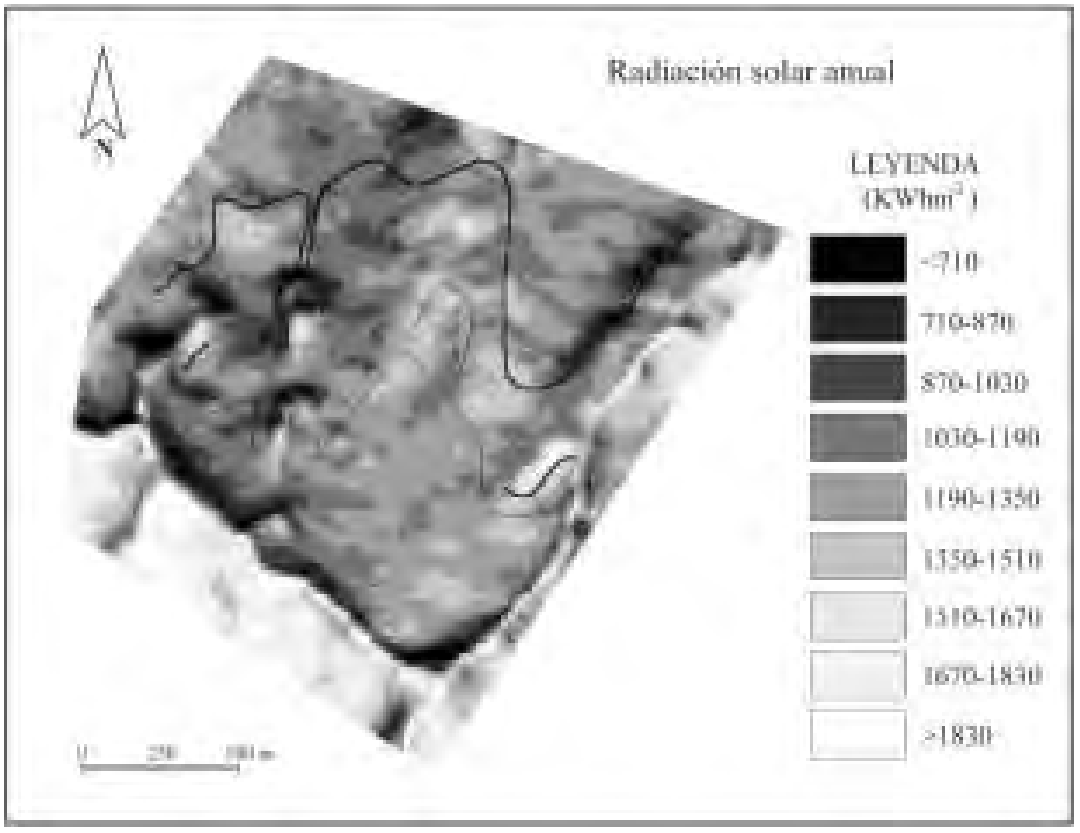

Figura 11. Cartografía de la radiación solar anual. 
Tabla 2. Sectores con valores de radiación solar elevados.

\begin{tabular}{|c|c|c|c|c|c|}
\hline Sectores & $\begin{array}{c}\text { Rad. verano } \\
\text { Kwhm }\end{array}$ & $\begin{array}{c}\text { Rad. solsticio ver. } \\
\text { Whm }\end{array}$ & $\begin{array}{c}\text { Rad. invierno } \\
\text { Kwhm }^{-2}\end{array}$ & $\begin{array}{c}\text { Rad. solsticio inv. } \\
\text { Whm }^{-2}\end{array}$ & $\begin{array}{c}\text { Rad. anual } \\
\text { Kwhm }^{-2}\end{array}$ \\
\hline 1 & 640 & 7.436 & 146 & 455 & 1.478 \\
\hline 2 & 669 & 7.573 & 171 & 722 & 1.578 \\
\hline 3 & 635 & 7.117 & 207 & 836 & 1.592 \\
\hline 4 & 567 & 6.847 & 104 & 438 & 1.281 \\
\hline 5 & 670 & 7.625 & 200 & 732 & 1.651 \\
\hline 6 & 628 & 7.324 & 146 & 496 & 1.463 \\
\hline 7 & 643 & 7.512 & 141 & 475 & 1.487 \\
\hline 8 & 687 & 7.689 & 229 & 1.186 & 1.742 \\
\hline 9 & 700 & 7.767 & 242 & 1.439 & 1.812 \\
\hline 10 & 628 & 7.061 & 179 & 594 & 1.504 \\
\hline 11 & 690 & 7.821 & 188 & 850 & 1.664 \\
\hline 12 & 630 & 7.431 & 123 & 489 & 1.425 \\
\hline
\end{tabular}

Mientras que en el primer caso influyó la localización altitudinal de la zona, en los otros dos se conjugaron valores muy elevados de radiación (los sectores 8 y 9 registran la radiación anual más elevada de los 12 analizados, con 1.742 y $1.812 \mathrm{KWhm}^{-2}$, respectivamente) y una escasa capacidad de acumulación nival, ya que en ese tramo el glaciar funcionaba como un apéndice de escaso dinamismo adosado a la cresta de los Portillones. La radiación recibida en los sectores 2, 5 y 11 (en estos dos últimos se han registrado el tercer y cuarto valor anual más elevados de los 12 sectores estudiados, con 1.651 y $1.664 \mathrm{KWhm}^{-2}$, respectivamente), propició ya la fusión del glaciar en esas áreas en 1914-20. Entre esa fecha y 1957, la degradación glaciar se manifiesta en los sectores 3 y 7 completándose, en esta última zona, la separación definitiva del glaciar del arco morrénico principal correspondiente a la PEH. En 1981, se detectan cambios menores que afectan al extremo septentrional del tramo occidental del glaciar y al apéndice emplazado en el extremo nororiental del tramo oriental del mismo asociados, respectivamente, con los sectores de radiación elevada 4 y 7. En 1990 se hace evidente la degradación de la zona occidental de la lengua central del glaciar, ligada a los altos valores calculados para los sectores 6 y 10. Por último, en 1997-99 se constata ya la fragmentación de los dos cuerpos glaciares y la desaparición de una parte del tramo oriental de la lengua glaciar, hechos relacionados de nuevo, respectivamente con los sectores de radiación elevada 10 y 7.

Es interesante resaltar el papel jugado en la degradación del glaciar por los grandes escarpes rocosos de la cresta que se prolonga hacia el norte desde el Pico Mir, y de la divisoria intermedia que separa los subcircos occidental y oriental de la Maladeta. Sus vertientes orientales (sectores 3, 5 y 10) reciben unos elevados valores de radiación, particularmente notables en los meses invernales (Figs. 12 y 13). El albedo, bajo en super- 


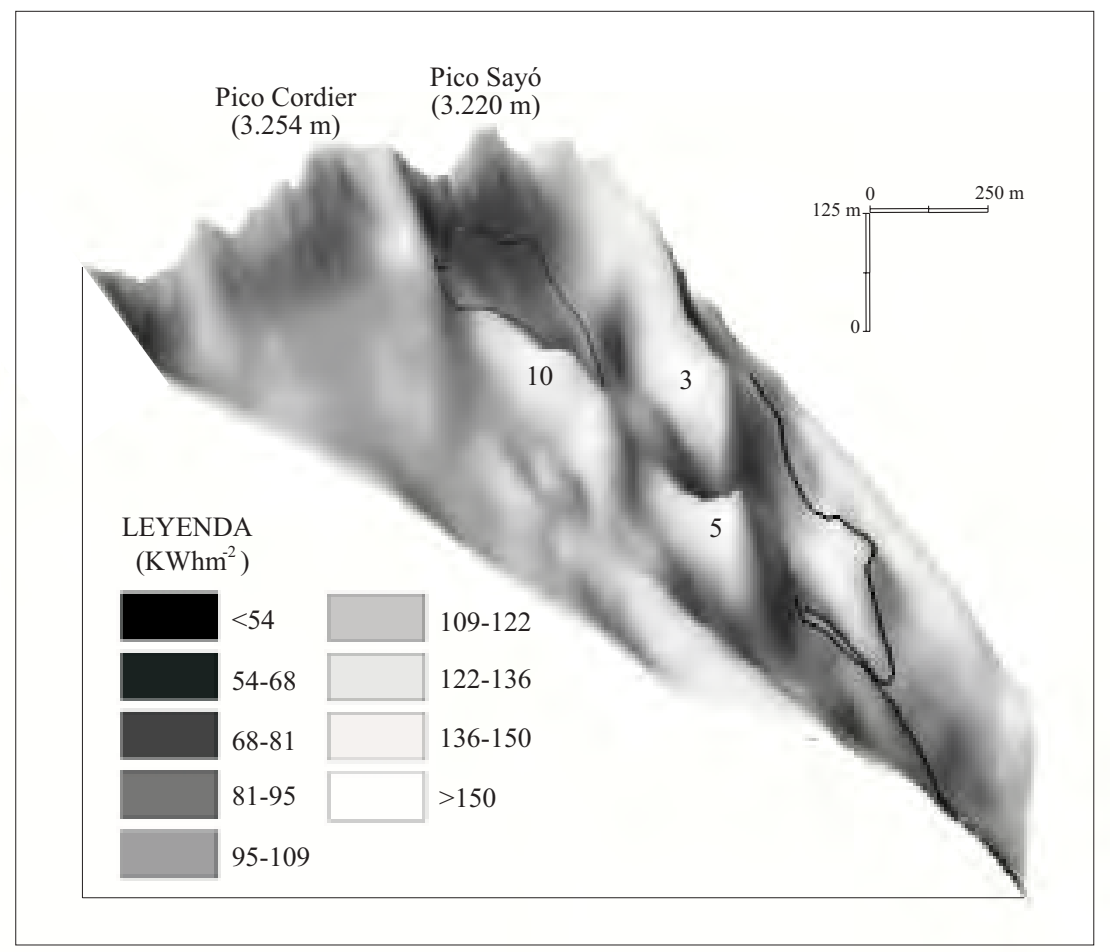

Figura 12. Panorámica en 3D del sector occidental del circo de la Maladeta con superposición de los valores de radiación solar invernal. Se indican los sectores con valores de radiación elevados 3, 5 y 10, y aparecen dibujados los arcos morrénicos de la PEH y el perímetro del glaciar Occidental de la Maladeta.

ficies rocosas desnudas como las citadas (en torno al 20-30\%; Barry, 1981), que permanecen libres de nieve durante prácticamente todo el año, favorece su calentamiento y, por conducción, el de las masas de aire adyacentes, ayudando a explicar la fusión de la nieve y el hielo en las proximidades de esas áreas, evidenciado desde comienzos del siglo XX.

Respecto a la evolución futura de ambos cuerpos, mientras que en el pequeño glaciar Occidental no existen ya sectores con radiación solar elevada que puedan degradarlo con rapidez, en el glaciar Oriental hay que resaltar la importancia de los mencionados sectores 6 y 7, que pueden llegar a provocar próximamente un estrechamiento considerable de la lengua central del glaciar. Importante será también observar las repercusiones en los procesos de acumulación dentro del sector 12 en condiciones climáticas como las registradas en las últimas dos décadas, caracterizadas por una reducción marcada de los aportes de precipitación nival (Chueca et al., 2003a, b, c; López Moreno et al., 2004a, b). 


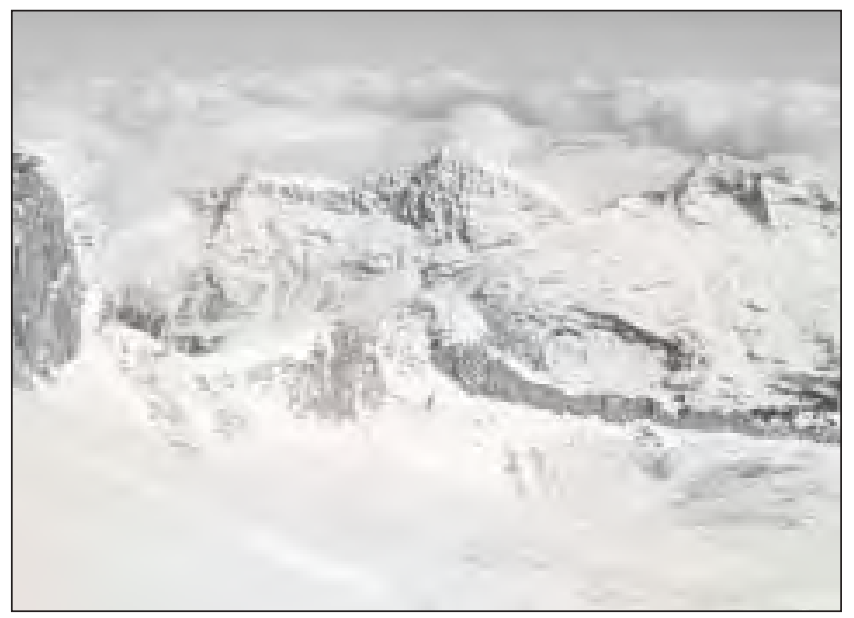

Figura 13. Vista invernal desde la parte media del glaciar Oriental de la Maladeta hacia los picos de Salvaguardia y La Mina. A la izquierda se aprecian los escarpes rocosos verticalizados de las dos unidades que constituyen la divisoria que separa los subcircos occidental y oriental de la Maladeta (sectores 10 y 5 en la cartografía de valores de radiación).

\subsubsection{Sectores con valores de radiación reducidos}

En este caso, se han seleccionado como significativos 12 sectores (sectores A-L) que reciben unos aportes de radiación reducidos en comparación con el resto del circo (Figs. 7-11; Tabla 3). El sector A, aunque emplazado fuera del área estudiada, se menciona por su importancia a la hora de explicar la prolongación hacia el circo de Alba del glaciar de la Maladeta en el último Máximo de la PEH. Los sectores B, C y F, favorecieron la permanencia del hielo en ese tramo occidental del glaciar desde 1901-04 hasta 1934-35. El sector D representa prácticamente la única anomalía en el patrón identificado en el subapartado anterior, donde se asociaban sectores con radiación elevada a zonas de degradación del glaciar. Es una zona con una radiación anual relativamente baja $\left(872 \mathrm{KWhm}^{-2}\right)$ pero en la que se constata la desaparición del hielo ya en 1901-04, antes incluso que en su vecino sector 2. La explicación a este hecho no es sencilla, aunque podría radicar en la incidencia lógica del bajo emplazamiento altitudinal (en esta zona se registra la menor altitud de todo el perímetro glaciado durante el último Máximo de la $\mathrm{PEH}$, próxima a los 2.500 m s.n.m.) y en el hecho de que la salida principal del agua de fusión del glaciar discurre precisamente por ese tramo, favoreciendo los procesos de degradación del cuerpo de hielo en un tramo distal con espesores reducidos. El sector E contribuyó a la conservación del sector noroccidental del tramo occidental del glaciar hasta 1957. En la actualidad, el glaciar Occidental apoya su conservación en la existencia de sectores como el G (donde se registra el tercer valor más bajo de radiación anual de los 12 analizados: 641 $\mathrm{KWhm}^{-2}$ ), y el tramo umbroso de pie de cresta que une los sectores I y J (donde se regis- 
Tabla 3. Sectores con valores de radiación solar reducidos.

\begin{tabular}{|c|c|c|c|c|c|}
\hline Sectores & $\begin{array}{c}\text { Rad. verano } \\
\text { Kwhm }^{-2}\end{array}$ & $\begin{array}{c}\text { Rad. solsticio ver. } \\
\text { Whm-2 }\end{array}$ & $\begin{array}{c}\text { Rad. invierno } \\
\text { Kwhm }^{-2}\end{array}$ & $\begin{array}{c}\text { Rad. solsticio inv. } \\
\text { Whm }^{-2}\end{array}$ & $\begin{array}{c}\text { Rad. anual } \\
\text { Kwhm }^{-2}\end{array}$ \\
\hline A & 260 & 4.430 & 61 & 366 & 685 \\
\hline B & 299 & 3.589 & 61 & 240 & 649 \\
\hline C & 361 & 4.226 & 69 & 284 & 775 \\
\hline D & 387 & 5.365 & 65 & 385 & 872 \\
\hline E & 385 & 4.768 & 60 & 348 & 824 \\
\hline F & 370 & 5.208 & 63 & 379 & 868 \\
\hline G & 255 & 4.156 & 55 & 331 & 641 \\
\hline H & 455 & 6.043 & 75 & 410 & 1.040 \\
\hline I & 300 & 3.627 & 63 & 237 & 657 \\
\hline J & 240 & 3.893 & 62 & 365 & 611 \\
\hline K & 318 & 3.979 & 76 & 344 & 716 \\
\hline L & 230 & 3.669 & 58 & 354 & 581 \\
\hline
\end{tabular}

tra el segundo valor más bajo: $611 \mathrm{KWhm}^{-2}$ ); los tres han influido en su conservación prácticamente sin cambios durante las dos últimas décadas. El glaciar Oriental, por su parte, mantiene su morfología en lengua gracias a la existencia de unos valores de radiación reducidos en el sector $\mathrm{H}$, en la zona central del circo; la conservación de la nieve en su zona de acumulación se ve favorecida en el tramo de pie de cresta que une los sectores K y L (en este último, ubicado bajo el Pico de la Maladeta, se registran los valores anuales de radiación más bajos de los 12 analizados, con $581 \mathrm{KWhm}^{-2}$ ).

Adicionalmente a la información expuesta por sectores, el examen de la cartografía evidencia que, globalmente, el subcirco donde se aloja actualmente el glaciar Occidental recibe una cantidad de radiación solar más reducida (en torno a un $10 \%$ menor) que el subcirco donde se emplaza el glaciar Oriental. Las diferencias en la radiación media estimada para cada subcirco (medidas desde la zona de crestas hasta las correspondientes morrenas de la PEH), en cada uno de los cinco períodos examinados, son significativas, fundamentalmente en el período estival y a escala anual: 1) subcirco Occidental: valor estival: $475 \mathrm{KWhm}^{-2}$; valor solsticio verano: $5.854 \mathrm{Whm}^{-2}$; valor invernal: $98 \mathrm{KWhm}^{-2}$; valor solsticio invierno: $410 \mathrm{Whm}^{-2}$; valor anual: $1.084 \mathrm{KWhm}^{-2}$; 2) subcirco Oriental: valor estival: $535 \mathrm{KWhm}^{-2}$; valor solsticio verano: $6.498 \mathrm{Whm}^{-2}$; valor invernal: 103 $\mathrm{KWhm}^{-2}$; valor solsticio invierno: $451 \mathrm{Whm}^{-2}$; valor anual: $1.207 \mathrm{KWhm}^{-2}$. En la Tabla 4 se recogen, de forma complementaria, los valores máximos y mínimos absolutos de radiación estimados para cada subcirco en los cinco períodos analizados aunque, en estos casos, el patrón observado desaparece. El buen desarrollo longitudinal alcanzado por el glaciar en su extremo occidental durante el último Máximo de la PEH se explica por tanto, pese a la menor extensión del subcirco en el que se aloja, por la morfología cerrada y escarpada del mismo, que ha controlado y restringido el tiempo de exposición 
Tabla 4. Valores de radiación solar medios, mínimos absolutos y máximos absolutos para los subcircos occidental y oriental de la Maladeta.

\begin{tabular}{|l|c|c|c|c|c|c|}
\hline & & $\begin{array}{c}\text { Rad. verano } \\
\text { Kwhm }^{-2}\end{array}$ & $\begin{array}{c}\text { Rad. solst. ver. } \\
\text { Whm }\end{array}$ & $\begin{array}{c}\text { Rad. invierno } \\
\text { Kwhm }^{-2}\end{array}$ & $\begin{array}{c}\text { Rad. solst. inv. } \\
\text { Whm }^{-2}\end{array}$ & $\begin{array}{c}\text { Rad. anual } \\
\text { Kwhm }^{-2}\end{array}$ \\
\hline & Med. & 475 & 5.854 & 98 & 410 & 1.080 \\
\hline Mal. Occidental & Mín. & 215 & 3.328 & 44 & 96 & 556 \\
\hline & Máx. & 741 & 8.188 & 306 & 1.961 & 1.990 \\
\hline & Med. & 535 & 6.498 & 103 & 451 & 1.027 \\
\hline Mal. Oriental & Mín. & 209 & 3.317 & 55 & 213 & 550 \\
\hline & Máx. & 720 & 7.996 & 298 & 1.978 & 1.908 \\
\hline
\end{tabular}

del hielo glaciar frente a la radiación solar. La mayor amplitud del subcirco oriental propicia la recepción de valores de radiación más elevados, que en este caso se ven compensados por una acumulación potencial del manto nival y el hielo glaciar mucho mayor.

\section{Conclusiones}

El uso de modelos de radiación solar basados en el empleo de Sistemas de Información Geográfica en zonas de relieve contrastado permite el cálculo preciso de las influencias de la topografía a escala tanto de paisaje como local. Un ejemplo de estas técnicas aplicado al campo glaciar se ha mostrado en el presente trabajo. Dentro del circo de la Maladeta existen considerables variaciones en la insolación recibida que han tenido y tienen, sumándose a condicionantes climáticos básicos como las temperaturas y precipitaciones, un efecto significativo en el proceso de degradación y fragmentación post-Pequeña Edad del Hielo del glaciar en él alojado.

Los datos obtenidos en el glaciar de la Maladeta confirman los resultados obtenidos previamente en circos vecinos y, en particular, el fuerte papel de dos elementos: 1) la topografía: básica a la hora de generar contrastes solana-umbría que favorecen los procesos de ablación o de conservación del hielo a escala local, sobre todo en áreas como la pirenaica con desarrollo de aparatos glaciares de reducida extensión y espesor. El relieve abrupto del terreno en las zonas de montaña influye en la cantidad de insolaciónradiación incidente, al controlar estrechamente el tiempo de exposición al haz solar directo; en el caso del glaciar de la Maladeta, las variaciones estacionales en el juego de sombras que proyectan las paredes del circo matizan la radiación global recibida en los distintos sectores del mismo y han repercutido en su evolución desde el último Máximo de la PEH; y 2) el efecto albedo: el albedo varía con el tipo de cubierta o superficie que aparece en el circo glaciar según la época del año considerada. Una cubierta de nieve reciente (típica de la estación invernal o primaveral en buena parte de la caja glaciar), refleja el $80-90 \%$ de la radiación que recibe. La nieve vieja o el hielo vivo (cubierta típica sobre el glaciar en la estación veraniega), presenta un albedo del 40-60\%. El roquedo desnudo (presente en determinadas zonas del circo, sobre todo en las más escarpa- 
das, durante prácticamente todo el año), registra valores promedio de albedo del 20$30 \%$. En estos últimos casos, y particularmente, como ya hemos mencionado, en el de la roca desnuda, la importancia de los procesos de fusión asociados al calentamiento de esas superficies y las masas de aire próximas aumenta de una forma considerable.

En el contexto general de la deglaciación subactual y actual, los resultados pirenaicos resultan representativos de las tendencias observadas en otras montañas de latitud media del ámbito mediterráneo que han experimentado un aumento constante en sus líneas de equilibrio glaciar durante el siglo XX a la par que una secuencia casi continua de balances de masa negativos. Éste ha sido el caso de los pequeños glaciares de los Alpes Marítimos meridionales (Gellatly et al., 1994a; Pappalardo, 1999), los Apeninos centrales (Gellatly et al., 1994b; D’Orefice et al., 2000) o Sierra Nevada (Messerli, 1980; Gómez Ortiz y Salvador, 1997). El control de la topografía en la conservación de pequeños aparatos glaciares como los pirenaicos, en desequilibrio con las actuales condiciones climáticas, ha sido también apuntado en varios sectores africanos por Kruss y Hastenrath (1987) y Hastenrath y Greischar (1997).

En trabajos futuros, la aplicación del modelo de radiación solar por áreas adoptado aquí puede arrojar resultados interesantes en otras zonas del Pirineo, ayudando a precisar la relación existente entre la radiación solar y el desarrollo glaciar en las etapas más recientes del Holoceno.

\section{Agradecimientos}

Este trabajo se ha realizado en el marco de los proyectos H-9007CMA "Estudio de la dinámica de los glaciares del Pirineo aragonés", financiado por el Gobierno de Aragón, y UZ2002-HUM-01 "Estudio de la dinámica glaciar en el Pirineo español en el contexto del cambio climático: correlación con reconstrucciones dendroclimáticas termo-pluviométricas", financiado por la Universidad de Zaragoza.

\section{Referencias bibliográficas}

BARRY, R.G. (1981). Mountain weather and climate. Methuen, London, 313 pp.

ChuecA, J. (1996). Estimación de la radiación incidente en el glaciar del Aneto (Pirineo central): repercusiones en su proceso de desarrollo y deglaciación. En Pérez Alberti, A., Martini, P., Chesworth, W. y Martínez Cortizas, A. (Eds.). Dinámica y evolución de Medios Cuaternarios, Xunta de Galicia, Santiago de Compostela, 183-190.

Chueca, J. y Julián, A. (1994). El medio natural de la Alta Ribagorza: macizo de la Maladeta. Col. Naturalia, Madrid, 155 p.

Chueca, J. y Julián, A. (1996). Datación de depósitos morrénicos de la Pequeña Edad del Hielo: macizo de la Maladeta. En Pérez-Alberti, A., Martini, P., Chesworth, W. y Martínez-Cortizas, A. (Eds.). Dinámica y evolución de Medios Cuaternarios, Xunta de Galicia, Santiago de Compostela, 171-182. 
Chueca, J. y Julián, A. (2004). Relationship between solar radiation and the development and morphology of small cirque glaciers (Maladeta mountain massif, Central Pyrenees, Spain). Geografiska Annaler, 86 A (1): 81-89.

Chueca, J., Peña, J.L., Lampre, F., García Ruiz, J.M. y Martí Bono, C. (1998). Los glaciares del Pirineo aragonés: estudio de su evolución y extensión actual. Universidad de Zaragoza, Zaragoza, 104 pp.

Chueca, J., Julián, A., Saz, M.A., Creus, J., López Moreno, J.I. y Lapeña, A. (2001). Estudio de la evolución del glaciar de Coronas (macizo de la Maladeta; Pirineo central español) desde el final de la Pequeña Edad del Hielo hasta la actualidad, y de su relación con el clima. Boletín Glaciológico Aragonés, 2: 81-115.

Chueca, J., Julián, A. y López Moreno, J.I. (2003a). Variations of Glaciar Coronas, Pyrenees, Spain, during the 20th century. Journal of Glaciology, 49 (166): 449-455.

Chueca, J., Julián, A., SAz, M.A., Creus, J. y López Moreno, J.I. (2003b). El glaciar de la Maladeta (Pirineo central español): análisis de su evolución desde la Pequeña Edad del Hielo y de su relación con factores climáticos. Cuaternario y Geomorfología, 17: 41-55.

Chueca, J., Julián, A., Saz, M.A., Creus, J. y López Moreno, J.I (2003c). Glacier extent evolution in the Spanish Pyrenees since the Little Ice Age and their relationship with climate: examples from the Maladeta massif area. Geophysical Research Abstracts, Vol. 5: 13388.

Copons, R. y Bordonau, J. (1994). La Pequeña Edad del Hielo en el Macizo de la Maladeta (Alta cuenca del Ésera, Pirineos centrales). En Martí Bono, C. y García Ruiz, J.M. (Eds.). El glaciarismo surpirenaico: nuevas aportaciones, Geoforma Ediciones, Logroño, 111-124.

Copons, R. y Bordonau, J. (1997). El registro glaciar correspondiente a la Pequeña Edad del Hielo en la Península Ibérica. En Ibáñez, J.J., Valero, B.L. y Machado, C. (Eds.). El paisaje mediterráneo a través del espacio y del tiempo. Implicaciones en la desertificación, Geoforma Ediciones, Logroño, 295-310.

D’Orefice, M., Pecci, M., Smiraglia, C. y Ventura, R. (2000). Retreat of Mediterranean glaciers since the Little Ice Age: case study of Ghiacciaio del Calderone, Central Apennines, Italy. Arctic, Antarctic and Alpine Research, 32 (2): 197-201.

DubaYAH, R. y Rich, P.M. (1995). Topographic solar radiation models for GIS. International Journal of Geographic Information Systems, 9: 405-413.

FLINT, A.L. y CHILDS, S.W. (1987). Calculation of solar radiation in mountainous terrain. Agriculture and Forest Meteorology, 40: 233-249. 
Fu, P. y Rich, P.M. (2000). The Solar Analyst 1.0. User manual. Helios Environmental Modeling Institute, LLC, Vermont, $48 \mathrm{pp}$.

FunK, M. y HoElzle, M. (1992). A model of potential direct solar radiation for investigating ocurrences of mountain permafrost. Permafrost and Periglacial Processes, 3: 139-142.

Gellatly, A.F., Grove, J.M., Latham, R. y Parkinson, R.J. (1994a). Observations of the glaciers in the Southern Maritime Alps (Italy). Revue de Géomorphologie Dynamique, 43 (3): 93-107.

Gellatly, A.F., Smiraglia, C., Grove, J.M. y Latham, R. (1994b). Recent variations of Ghiacciaio del Calderone, Abruzzi, Italy. Journal of Glaciology, 40 (136): 486-490.

Gómez Ortiz, A. y Salvador, F. (1997). El glaciarismo de Sierra Nevada, el más meridional de Europa. En Gómez Ortiz, A. y Pérez Alberti, A. (Eds.). Las huellas glaciares de las montañas españolas. Universidade de Santiago de Compostela, Santiago de Compostela, 385-430.

Hastenrath, S. y Greischar, L. (1997). Glacier recession on Kilimanjaro, East Africa, 1912-89. Journal of Glaciology, 43 (145): 455-459.

Heggem, E.S.F., Etzelmüller, B. y Berthling, I. (2001). Topographic radiation balance models: sensitivity and application in periglacial geomorphology. Norsk Geografisk Tidsskrift, 55: 203-211.

Hetrick, W.A., Rich, P.M., Barnes, F.J. y Weiss, S.B. (1993). GIS-based solar radiation flux models. American Society for Photogrammetry and Remote Sensing Technical Papers, 3: 132-143.

IQbal, M. (1983). An introduction to solar radiation. Academic Press, New York, 223 pp.

JoAnne, A. (1862). Itinéraire général de la France. Les Pyrénées. Hachette, Paris, $767 \mathrm{pp}$.

Julián, A., Chueca, J., PeñA, J.L., LóPez Moreno, J.I. y Lapeña, A. (2001). Dinámica de los glaciares del Pirineo Aragonés: resultados de la campaña glaciológica del año 1999. Boletín Glaciológico Aragonés, 2: 13-36.

Kruss, P.D. y HastenRath, S. (1987). The role of radiation geometry in the climate response of Mount Kenya's glaciers. Part 1. Horizontal reference surfaces. J. Climatology, 7 (5): 493-505.

LAMPre, F. (1994). La línea de equilibrio glacial y los suelos helados en el macizo de la Maladeta (Pirineo aragonés): evolución desde la Pequeña Edad del Hielo y situación actual. En Martí Bono, C. y García Ruiz, J.M. (Eds.). El glaciarismo surpirenaico: nuevas aportaciones, Geoforma Ediciones, Logroño, 125-142. 
LAmpre, F. (1996). Evolución glacial de Ballibierna (Macizo de la Maladeta, Pirineo Aragonés). En Pérez-Alberti, A., Martini, P., Chesworth, W. y Martínez-Cortizas, A. (Eds.). Dinámica y evolución de Medios Cuaternarios, Xunta de Galicia, Santiago de Compostela, 143-155.

López Moreno, J.I., ChuecA, J. y Julián, A. (2004a). Recent glacial evolution related to snow accumulation in the Spanish Pyrenees. Geophysical Research Abstracts, Vol. 6: 02049.

López Moreno, J.I., ChuecA, J. y Julián, A. (2004b). Links between NAO index, winter and spring snow accumulation and glacier extent evolution in the Maladeta massif (Spanish Pyrenees) since the 1950‘s. 32nd Int. Geol. Congr., Abs. Vol. 1: 238-9.

Martí Bono, C. y García RuIz, J.M. (Eds.) (1994). El glaciarismo surpirenaico: nuevas aportaciones. Geoforma Ediciones, Logroño, $142 \mathrm{pp}$.

Martínez, R. y García, F. (1994). Trabajos de glaciología en el glaciar de la Maladeta. Campaña 1991-92. En MOPTMA (Ed.). La nieve en las cordilleras españolas, MOPTMA, Madrid, 209-236.

Martínez, R. y García, F., Macheret, Y., Navarro, J. y Bisbal, L. (1997). El sustrato subglaciar y la estructura interna de los glaciares del Aneto y la Maladeta cartografiados por geo-radar de ultra-alta frecuencia (UHF). En MMA (Ed.): La nieve en las cordilleras españolas, Ministerio de Medio Ambiente, Madrid, 227-249.

Martínez de Pisón, E. y Arenillas, M. (1988). Los glaciares actuales del Pirineo español. En MOPU (Ed.): La nieve en el Pirineo español, MOPU, Madrid, 29-98.

Messerli, B. (1980). Mountain glaciers in the Mediterranean area and in Africa. World Glacier Inventory Workshop Publication, 126: 197-211.

PACKe, C. (1867). A guide to Pyrenees. Longmans Green and Co., London, 301 pp.

PAPPAlARDO, M. (1999). Remarks upon the present-day condition of the glaciers in the Italian Maritime Alps. Geografia Fisica e Dinamica Quaternaria, 22: 79-82.

Parrot, F. (1823). Reise in den Pyrenäen. G. Reiner, Berlin, 145 pp.

Rich, P.M., Dubayah, R., Hetrick, W.A. y SAVInG, S.C. (1994). Using viewshed models to calculate intercepted solar radiation: applications in ecology. American Society for Photogrammetry and Remote Sensing Technical Papers, 4: 524-529.

Schrader, F. (1894). Sur l'étendue des glaciers des Pyrénées. Annuaire du Club Alpin Français, 21: 403-423.

VARLEY, M.J. y BeVEn, K.J. (1996). Modelling solar radiation in steeply sloping terrain. International Journal of Climatology, 16 (1): 93-104. 